\title{
Vegetarianism and colorectal cancer risk in a low-selenium environment: effect modification by selenium status? A possible factor contributing to the null results in British vegetarians
}

\author{
Jakub G. Sobiecki ${ }^{1,2,3}$
}

Received: 24 November 2015 / Accepted: 14 December 2016 / Published online: 13 February 2017

(C) The Author(s) 2017. This article is published with open access at Springerlink.com

\begin{abstract}
Background Despite the consistent findings of lower total cancer incidence in vegetarians than in meat-eaters in the UK, the results of studies of colorectal cancer (CRC) risk in British vegetarians have largely been null. This was in contrast to the hypothesis of a decreased risk of CRC in this population due to null intake of red and processed meats and increased intake of fibre. Although the data are inconsistent, it has been suggested that selenium (Se) status may influence CRC risk.

Methods A literature review was performed of studies on CRC risk in vegetarians, Se intakes and status in vegetarians, and changes of Se intakes and status in the UK throughout the follow-up periods of studies on CRC risk in British vegetarians.

Results Vegetarians in the UK and other low-Se areas were found to have low Se intakes and status compared to nonvegetarians. There was some evidence of a reverse J-shaped curve of Se intakes and status in the UK throughout the last three decades. These presumed patterns were followed by the changes in CRC mortality or incidence in British vegetarians during this period.
\end{abstract}

Jakub G. Sobiecki

jacob.sobiecki@ceu.ox.ac.uk; j.sobiecki@imperial.ac.uk

1 Cancer Epidemiology Unit, Nuffield Department of Population Health, Richard Doll Building, University of Oxford, Roosevelt Drive, Oxford OX3 7LF, UK

2 Department of Epidemiology and Biostatistics, School of Public Health, Imperial College London, St Mary's Campus, London W2 1PG, UK

3 Department of Paediatrics, Nutrition and Metabolic Disorders, Children's Memorial Health Institute, Al. Dzieci Polskich 20, Warsaw 04-730, Poland
Conclusions Available data on Se intake and status in British vegetarians, as well as the relationship between their secular changes in the UK and changes in CRC risk in this dietary group, are compatible with the hypothesis that low Se status may contribute to the largely null results of studies of CRC risk in vegetarians in the UK.

Keywords Vegetarian · Selenium · Colorectal cancer . United Kingdom

\section{Introduction}

According to the World Cancer Research Fund (WCRF), there is convincing evidence that processed (i.e. preserved by smoking, curing or salting, or addition of chemical preservatives) and red meats, as well as foods high in fibre, are causative risk factors for colorectal cancer (CRC), with the former increasing and the latter decreasing its risk [1]. The recent evaluation of the carcinogenicity of these foods by the International Agency for Research on Cancer has corroborated the findings of the WCRF by classifying processed meats as Group 1 carcinogen ("carcinogenic to humans") and red meat as Group 2A carcinogen ("probably carcinogenic to humans"), based chiefly on the evidence for CRC [2]. It is estimated that minimizing the intake of processed and red meats (to nil intake) could prevent $21 \%$ of cases of CRC in the UK, while eating a high-fibre ( $\geq 23 \mathrm{~g}$ fibre per day) diet could prevent $12 \%$ of cases [3].

In light of these findings, it seems reasonable to propose a vegetarian diet emphasizing minimally processed plantbased foods as a model for risk reduction of CRC. Indeed, a $46 \%$ reduction of 6 year incident colon cancer risk (rectal cancer and CRC were not reported), but not CRC mortality [4], has been observed in American vegetarians within 
the Adventist Health Study 1, compared to otherwise similar members of the Adventist Church [5]. Also, the authors found a positive association of total, red and white meat intakes with colon cancer risk; a negative association between legume intake and this risk; and evidence of interaction between high red meat intake, low legume intake, and high body mass in increasing the risk [5].

In the largest cohort study which purposely recruited a high proportion of vegetarians - the ongoing Adventist Health Study 2-after a mean follow-up of 7.3 years, the relative hazard of incident CRC was $22 \%$ lower in all diet groups with reduced or nil meat intake (semivegetarians, pesco-vegetarians, vegetarians and vegans) combined than in non-vegetarians, and the observed risk reduction in colon, but not rectal cancer in all types of vegetarians combined was close to statistical significance (HR 0.81; $95 \%$ CI: $0.65-1.00, p=0.053$ ) [6]. In analyses of separate vegetarian diet groups, only pesco-vegetarians had a significantly reduced risk of CRC incidence (HR 0.57 ; 95\% CI: $0.40-0.82$ ).

The results of studies in British vegetarians-historically the only cohorts other than the Adventist cohorts with sufficient sample sizes to detect differences in CRC rates between vegetarians and non-vegetarians-have largely been null, both in regard to CRC mortality $[7,8]$ and CRC incidence [9-11].

\section{CRC risk in British vegetarians-an overview of the published findings}

Six reports on CRC risk in British vegetarians were published thus far from three studies: Health Food Shoppers Study (HFSS) [7], the Oxford Vegetarian Study (OVS) [8], the Oxford arm of the European Prospective Investigation into Cancer (EPIC-Oxford) study [9, 12] and combined analyses from the EPIC-Oxford and the OVS [10,11]. The details on study design and recruitment of subjects have been described elsewhere [13-15].

Briefly, the HFSS and the OVS recruitment took place in the 1970s and early 1980s, respectively, with follow-up until the late 1990s. Both cohorts comprised approximately 11,000 subjects each, with health-conscious non-vegetarians and a large proportion of vegetarians (ca. $40 \%$ ). In the ongoing EPIC-Oxford study, a cohort of 65,429 subjects was recruited between 1993 and 1999, comprising ca. 30\% of vegetarians, $15 \%$ of fish-eaters (pesco-vegetarians) and $4 \%$ of vegans. The remaining meat-eaters included ca. $80 \%$ of health-conscious individuals, with the rest being recruited from the general population. In all three studies, follow-up was by record linkage with the National Health Service Central Register.
In both the HFSS and the OVS, the CRC mortality risk was insignificantly lower in vegetarians than in non-vegetarians at 0.85 (95\% CI: 0.52-1.39) [7] and 0.85 (95\% CI: 0.55-1.32) [8], respectively, after a mean follow-up of 21 and 17 years, respectively.

In the EPIC-Oxford study, the relative rate of CRC incidence was in fact higher in vegetarians than in meat-eaters after a mean follow-up of 10.7 years (RR 1.39; 95\% CI: 1.01-1.91), despite the total cancer incidence being borderline significantly lower $(P=0.052)$ by $11 \%$ in vegetarians [9]. Also, the standardized incidence ratio (SIR) of 101 (95\% CI: 79-128) suggested that vegetarians had incidence rate of CRC similar to average British citizens, while nonvegetarians (meat-eaters and fish-eaters combined) had significantly lower CRC SIR (84; 95\% CI: 73, 95). In line with these findings, the standardized mortality ratio (SMR) for CRC in EPIC-Oxford after the same mean follow-up was significantly lower in non-vegetarians than in the general UK population (SMR 67; 95\% CI: 54-82), but not in vegetarians (81; 95\% CI: 55-115) [12]. This was despite the SIRs and SMRs for all malignant neoplasms being significantly and substantially lower in both non-vegetarians and vegetarians than in the general population-all at approximately $70[9,12]$.

Subsequent reports of combined analyses of incident CRC risk from EPIC-Oxford and OVS were null after 12.2 years average follow-up (RR 1.12; 95\% CI: $0.87-$ 1.44) [10] and 14.9 years (RR 1.03; 95\% CI: 0.84-1.28) [11]. Again, this was despite the total cancer incidence in vegetarians being significantly lower than in meat-eaters by $12 \%$ in both publications. In the latter analysis, a decreased risk of CRC was observed in fish-eaters compared to meateaters (RR 0.66; 95\% CI: 0.48-0.92) [11].

It should be emphasized that chance may be one plausible, at least partial explanation for the rather surprising findings of increased CRC risk in vegetarians, given the null results in all other publications from this population and the lower end of the $95 \%$ confidence interval being close to 1 . It is important not to make a case against the established, negative health effects of processed and red meats or dietary patterns including these foods by selectively citing the results of increased CRC risk in British vegetarians, as it has been done in the literature in relation to CRC [16], as well as coronary heart disease and type 2 diabetes [17].

\section{Possible causes of differences in CRC risk between American and British vegetarians}

Fraser has proposed that the characteristics of the dietary pattern of the EPIC-Oxford cohort may be important to the inconsistency between the result of American and British 
studies of CRC risk in vegetarians [18]. Other than null or episodic intake of meat in vegetarians and increased intake of fruit and vegetables, their dietary pattern is similar to that of the UK population; however, none of its characteristics [19] seem to be particularly relevant to CRC risk, at least in light of the current knowledge [1].

Also, it should be noted that the intake of meat in nonvegetarians in the EPIC-Oxford study is relatively low at a median of $65 \mathrm{~g} /$ day in men and $54 \mathrm{~g} /$ day in women [9]. For reference, the mean national intakes in British adults are estimated to be $130 \mathrm{~g}$ in men and $89 \mathrm{~g}$ in women [20]. It appears that the differences in nutrient intakes between vegetarians and non-vegetarians are less pronounced in the EPIC-Oxford cohort, compared to those observed in the Adventist Health Study-2 [6, 21, 22]. However, it may be at least in part due to the differences in the food frequency questionnaires (FFQ) used in the studies, with the AHS2 FFQ (unlike the EPIC-Oxford FFQ), allowing participants to choose different multiples of the standard portion size. Due to the lower energy density of staple plant foods, such as whole grains and legumes, vegetarians may be more likely to consume larger portions than meat-eaters; therefore, a single serving size FFQ may underestimate their intakes of these foods and thus most nutrients.

When investigating the possible dietary factors influencing the CRC risk in British vegetarians, it is important to note that in contrast to the USA, the UK (as well as most of Europe) is a low-selenium (Se) area [23]. To illustrate the magnitude of the difference, mean daily Se intakes are approximately $40 \mu \mathrm{g}$ per day in Europe, and $93 \mu \mathrm{g}$ in American women and $134 \mu \mathrm{g}$ in American men [24]. For reference, the daily level of intake currently recommended in the UK for individuals is $1 \mu \mathrm{g}$ of Se per $\mathrm{kg}$ of body weight, which in practical terms translates to recommended intakes of 60 and $75 \mu \mathrm{g} /$ day for females and males, respectively [25].

Given that Se status has been implicated in cancer risk in humans $[24,26]$, and that vegetarians in low-Se areas have lower Se intake and status than non-vegetarians (Table 1), it seems prudent to explore the speculative hypothesis that it may have been involved in the CRC risk in the studies of British vegetarians.

Interestingly, there is scant evidence to support the notion that a vegetarian diet in the UK may upregulate some mechanisms involved in the development of CRC. Joosen et al. [27] carried out two small, randomized crossover studies comparing the short-term effect of a vegetarian diet with omnivorous diets containing either red or processed (nitrite-preserved) meats on endogenous nitrosation and DNA damage. In both of these comparisons, there were significantly more faecal water-induced DNA strand brakes in $\mathrm{CaCO}_{2}$ cells in the vegetarian diet groups, as measured by the comet assay. The measurement of faecal water genotoxicity suffers from considerable technical difficulties [28], and hence the described results should be interpreted with due caution. That being said, it is reasonable to expect at least one aspect of the vegetarian diet in the UK to negatively influence the CRC risk, given that its significantly decreased risk has not been observed in British vegetarians, despite no intake of red and processed meats and higher intake of fibre than that of meat-eaters $[1,15]$, as well as a higher frequency of bowel movements [29].

\section{Selenium and cancer in humans}

Se is an essential nutrient, which is utilized for the expression of 25 different selenoprotein-encoding genes. The majority - and possibly all—of the selenoproteins are involved in the regulation of the redox status [30]. Some of them, namely glutathione peroxidases (GPxs), $15 \mathrm{kDa}$ selenoprotein, Se-transport protein selenoprotein $\mathrm{P}$ (SePP) and thioredoxin reductases, have been implicated in tumourigenesis or cancer spread [26]. Although the biology of Se is highly suggestive of a protective effect against cancer, which indeed has been shown in various animal models [29], the findings from studies in humans have been conflicting. It is currently unclear whether or not $\mathrm{Se}$ intake has a direct influence on cancer risk in humans, and more specifically CRC risk in the context of the current review.

The WCRF Expert Panel has judged foods containing Se to be a probable factor decreasing the risk of prostate cancer, and that there is limited-suggestive evidence for the same effect of this food group in the context of CRC, lung and stomach cancers [31]. In the subsequent WCRF Continuous Update Project (CUP) report on prostate cancer, judgement was made in regard to "low blood levels of Se" rather than the intake of foods from this food group, and the level of evidence was downgraded to limited-suggestive [32]. In the WCRF CUP report on CRC, the level of evidence for selenium's effect on CRC risk was also downgraded (to limited-no conclusion), both in regard to foods containing Se and supplementary Se [1].

A recent Scientific Advisory Committee on Nutrition position statement on selenium and health concluded that "in the context of the levels studied, data do not suggest a protective association between higher Se intake or status in relation to prostate or lung cancers, and data are insufficient to establish whether or not selenium is associated with the risk of developing breast or colorectal cancers [33]". The 2014 update of the Cochrane review on Se and cancer prevention came to similar conclusions [34]. That being said, such reviews rely heavily on the results of two major trials described below, conducted in the American population with largely adequate baseline Se status. 


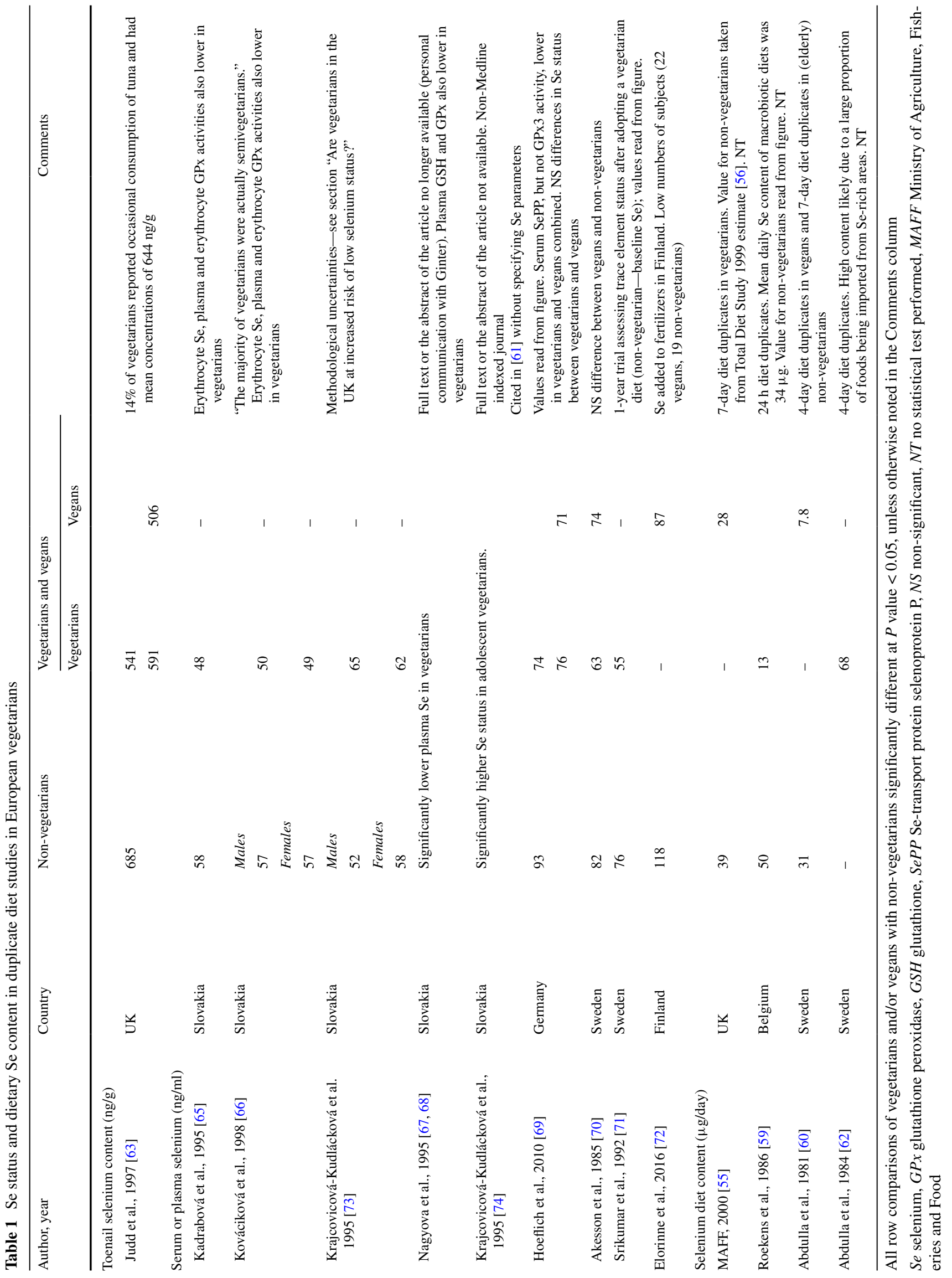


The strongest evidence of a protective effect of Se against CRC comes from the Nutritional Prevention of Cancer (NPC) trial-a double-blind, placebo-controlled randomized trial of treatment with $200 \mu \mathrm{g}$ Se per day in 1312 subjects from south-eastern USA with a history of non-melanoma skin cancer, which was also the primary outcome [35]. After a mean follow-up of 4.5 years, there was no effect of Se on the primary outcome, but there was a significant $50 \%$ reduction in cancer mortality, as well as reduction in cancer incidence of $37 \%$ for all cancers, $67 \%$ for prostate cancer, $58 \%$ for CRC and $46 \%$ for lung cancer. However, the follow-up was extended to 7.9 years in a nonblinded fashion, by the end of which period the incidence remained significantly reduced only for total $(25 \%)$ and prostate (52\%) cancers [36], as well as lung cancer in subjects in the bottom tertile of baseline plasma Se $(<106 \mathrm{ng} /$ ml) [37].

The results of the largest double-blind, placebo-controlled randomized trial to date $(35,533$ subjects), the Selenium and Vitamin E Cancer Trial (SELECT), investigating the effect of Se supplementation (200 $\mu \mathrm{g} /$ day) on prostate cancer incidence with CRC as one of the secondary outcomes, have been null [38]. However, the baseline Se status was likely too high for any potential benefit to manifest itself. The median baseline serum Se was $136 \mathrm{ng} / \mathrm{ml}$ [38], while in the NPC trial the median baseline plasma Se was 113 ng/ml [36] (plasma and serum Se assays yield similar values). Also, few subjects in the SELECT trial had baseline serum Se below $106 \mathrm{ng} / \mathrm{ml}$, which was the plasma Se range in the NPC trial for which there was the strongest evidence of beneficial effects of Se supplementation on prostate cancer risk. Concurrently, there was no evidence of benefit in the highest baseline Se status category (>123 ng/ $\mathrm{ml}$ ) in the NPC trial [36, 39].

Even before the results of SELECT were available, Rayman proposed that due to the lower Se status of Europeans, Europe was a more suitable geographical area for conducting a primary prevention Se trial the likes of SELECT, as stronger effects would be expected in such a population [26]. Other than the baseline Se status of the study population, another issue which is recommended to be taken into account in study design of future Se trials is the measurement of single nucleotide polymorphisms influencing Se metabolism, which may have contributed to the conflicting findings on Se and cancer risk in humans [40]. Moreover, Se status assessment itself represents a challenge, as relatively little is known about the performance of currently used biomarkers as indices of long-term Se exposure. In a recent pooled analysis of individual participant data from fifteen prospective studies, blood Se concentration (shortterm exposure biomarker) was not associated with risk of total prostate cancer, while nail Se concentration (longerterm exposure biomarker) was inversely associated with this risk [41]. These results call for more attention being paid to Se exposure assessment in future studies, as well as for a reappraisal of the Se-prostate cancer relationship.

In principle, the current understanding of the impact of Se on cancer risk, if any in humans, suggests that it is largely mediated via the influence of Se status on the expression of selenoproteins, with different selenoproteins having different saturation plasma/serum Se thresholds [30]. Both observational data in humans [42], as well as basic research on Se [43] suggest the existence of a U-shaped curve_or 'a split "Dr. Jekyll and Mr. Hyde" personality' of some selenoproteins, as illustratively described by Hatfield and colleagues [43] — of the Se status or intake and the anti- or pro-tumourigenic effects. Anti-tumourigenic effects of Se have been observed in animal studies utilizing doses of Se an order of magnitude higher than required for saturation of most selenoproteins' expression [30]. This implies that either non-selenoprotein Se compounds-i.e. low molecular weight Se-metabolites-exert such effects or some under-researched, and possibly even undiscovered, selenoprotein(s) (e.g. those expressed by immune cells) have substantially higher Se requirements for maximum expression.

In the context of observational studies, it is reasonable to assume that revealing a 'true' Se-cancer risk association may only be possible, when the range of Se statuses in the study sample encompasses both deficient or suboptimal, as well as optimal concentrations of selenoproteins relevant to a particular type of cancer [44].This may have been the case in the recently published case-control study nested in the whole EPIC cohort on Se status and CRC risk [45]. It found that serum levels of SePP were inversely associated with CRC risk, with the association being more apparent in women, while serum Se was significantly associated with CRC risk only in women, and not in both sexes combined. The finding of the associations being more evident in women is particularly relevant to the EPIC-Oxford cohort, in which women constitute $78 \%$ of all subjects (albeit no evidence of effect modification of CRC risk in vegetarians by sex was reported in any of the publications on cancer incidence or mortality in EPIC-Oxford [9-12]).

\section{Taking a step back-what is actually "selenium"?}

It should be emphasized that unlike many other minerals of nutritional relevance, dietary $\mathrm{Se}$ is not a discrete substance, but rather a group of compounds containing Se [46], which have different metabolic pathways [47], as well as half-lives and Se bioavailabilities (which are generally high) [48]. Simply drawing attention of a reader with basic knowledge of chemistry to the fact that Se has four oxidation states of -II, 0, IV and VI is likely to be instantaneously 
and intuitively informative of the biochemical diversity and complexity to be expected. Briefly, Se is present in foods mostly as inorganic Se (selenate, selenite), selenomethionine (SeMet), methylselenocysteine (MeSeCys) and selenocysteine (SeCyS) [46-50].

Selenite and SeMet are generally the predominant forms in plants commonly consumed by humans, with notable exceptions of the Se-accumulating cruciferous and allium vegetables, in which substantial proportions of total $\mathrm{Se}$ comprise of Se-methyl-selenocysteine and y-glutamyl-Semethyl-selenocysteine [46, 47]. For animal products, speciation of Se depends on the baseline Se status and whether or not the feed is fortified with inorganic Se [46, 47], which is a common practice in some low-Se countries, including the UK-albeit not mandatory and permissible only at a low level [51]. Provision of inorganic Se increases the SeCys content in animal tissues compared to animals eating Se-containing plant foods, which in turn increases the SeMet content of the tissues [46, 47]. It is thus of note that differences in Se speciation in animal products between the UK and high-Se areas of USA can be expected, which may be of relevance to the differences in relative risk of CRC between British and American vegetarians. Se speciation in fish and shellfish varies greatly between species and may include a substantial proportion of inorganic selenium [52]. Although Se content in this food group is generally highalbeit variable-it may be somewhat less available than from other foods [46-48].

Since the metabolic pathways of all Se-containing compounds intersect at a common metabolite, hydrogen selenide $\left(\mathrm{H}_{2} \mathrm{Se}\right)$, it is theoretically possible for all these compounds to be equally utilized for selenoprotein expression. However, due to high reactivity of selenides with oxygen and metals, $\mathrm{H}_{2} \mathrm{Se}$ may not be freely available in sufficient quantities as to not be a limiting factor in some of the $\mathrm{Se}$ metabolic pathways [50]. Also, there is a major difference between the two predominant dietary Se compounds, SeMet and SeCys, in that the former can be incorporated non-specifically into proteins by replacing methionine, which allows for storing Se in the organism [49]. This may offer a distinct advantage of prolonged maintenance of Se status by a given dose of Se compared to other Se compounds [49]. However, Se from SeMet—when proteinbound-may be less readily available for conversion to SeCys and further Se metabolism [53]. Indeed, it has been recently shown in a randomized clinical trial in healthy men that selenised yeast (a mixture of Se compounds), but not SeMet, was effective in reducing the levels of oxidative stress biomarkers at similar increases in plasma Se in both intervention arms [54]. The characteristics of SeMet outlined above may serve as a yet another alternative and/ or partial explanation for the conflicting results of the NPC trial, in which selenised yeast was used, and SELECT, which utilized SeMet [35, 38, 48, 49, 53, 54].

Appreciating the fact not all dietary Se is 'created equal' is important for critical interpretation of studies on health effects of Se, as well as the hypothesis presented in the current review.

\section{Are vegetarians in the UK at increased risk of low selenium status?}

A 7-day duplicate diet study in the UK has found the Se content of approximately 50 vegetarian diets to be $28 \mu \mathrm{g} /$ day [55], which was lower than the estimated $39 \mu \mathrm{g} /$ day intake of the general population $[55,56]$. Data on $\mathrm{Se}$ intakes in British vegans estimated from food records suggest insufficient intakes [57], however, unlike for many other nutrients, this is not a reliable measure of Se dietary intake due to large within-food variation of Se content [58]. Se content of vegetarian diets has also been evaluated by means of a duplicate diet study in Belgium [59] and in Sweden [60]. The mean Se content of $24 \mathrm{~h}$ duplicates of vegetarian diets from Belgium was only $13 \mu \mathrm{g}$, compared to $50 \mu \mathrm{g}$ in non-vegetarian diets and $34 \mu \mathrm{g}$ in macrobiotic diets (i.e. largely vegetarian diets, allowing low consumption of animal flesh, particularly fish, which are a good source of Se [61]). A 4-day duplicate vegan diet samples analysis from Sweden revealed daily Se content of only $7.8 \mu \mathrm{g}$, compared to the already low $31 \mu \mathrm{g}$ in a Swedish mixed diet of elderly subjects [62]. Surprisingly, a similar study by the same group regarding lactovegetarian diets found Se content of $68 \mu \mathrm{g} /$ day in men and $61 \mu \mathrm{g} /$ day in women [60]. According to the authors: "This [...]might partly be explained by the fact that many of the food items [...] were imported, and it is possible that these products were grown in areas that are rich in selenium."

Only one study directly assessing Se status in British vegetarians was identified. Based on the analysis of toenail concentrations of this mineral in the UK, Judd and colleagues have suggested that vegetarians and vegans may be at increased risk of Se deficiency [63]. The 57 vegetarians and vegans under study had mean toenail $\mathrm{Se}$ concentrations of $541 \mathrm{ng} / \mathrm{g}$, which was significantly lower than $685 \mathrm{ng} / \mathrm{g}$ in the 67 meat-eaters matched for sex and age. Also, these concentrations were significantly lower in vegans $(n=34)$ than in vegetarians $(n=23)$ at 506 vs $591 \mathrm{ng} / \mathrm{g}$. This may have been at least in part due to eight vegetarians who reported occasional consumption of tuna and had mean concentrations of $644 \mathrm{ng} / \mathrm{g}$. This study was published as a short communication only and unfortunately, it was not stated directly whether or not vegetarians and vegans under study dwelled in the same geographical 
area as non-vegetarian controls, who resided in Norfolk-a relatively high-Se area within the UK [63].

Plasma Se was assayed in selected participants of the whole EPIC cohort in the nested case-control study of Se status and prostate cancer risk, which included few vegetarians from the EPIC-Oxford cohort [64]. Overall, there were 10 vegetarians and fish-eaters (pesco-vegetarians) each, 56 meat-eaters and no vegans in this analysis. Mean plasma Se values were $68 \mathrm{ng} / \mathrm{ml}$ in vegetarians and $81 \mathrm{ng} / \mathrm{ml}$ in fisheaters, compared to $77 \mathrm{ng} / \mathrm{ml}$ in meat-eaters (unpublished data). The differences between diet groups were not tested for statistical significance due to the secondary nature of the data, and low numbers of vegetarians and fish-eaters. However, they are in agreement with the overall body of evidence showing lower Se status in vegetarians in low-Se areas and suggest that the same pattern may be present in the EPIC-Oxford cohort-which is one of the underlying assumptions for the hypothesis presented in the current review. (Similarly low numbers of vegetarians and fisheaters from the EPIC-Oxford cohort were included in the EPIC-nested case-control study of serum Se and SePP, and CRC risk [45] (personal communication with Hughes and Fedirko), also precluding an analysis of Se status by diet group in the EPIC-Oxford cohort).

Available data from other European, low-Se countries consistently [65-72], but not unanimously [73, 74], show lower blood parameters of Se status in vegetarians and vegans compared to non-vegetarians. The results of two studies by Krajcovicová-Kudlácková et al. [73, 74] from Bratislava, Slovakia, which have observed higher Se status in vegetarians than in non-vegetarians, represent the only discrepancy within the studies of Se status in European vegetarians. One of the two studies [74] was published in a non-Medline indexed journal and its full text or abstract is not available. It was only cited in the discussion of the other study [73] which found higher plasma Se in vegetarians, as evidence of previous similar findings (without specifying which Se status biomarkers were used in it). The authors did not provide an in-depth discussion of the possible reasons for the inconsistency of their findings with the rest of the literature. Also, the manuscript was lacking in information on preanalytical sample handling and adequate quality control measures, without which the validity of these data cannot be critically assessed. Similarly, no information was given on methods of recruitment of vegetarians and ascertainment of adherence to vegetarian diet. Should they have been self-reported vegetarians, a substantial proportion of them may have in fact been non-vegetarians [75]. Assuming the validity of the results, one potential explanation for these unexpected findings stems from the Swedish duplicate diet study reporting higher Se content in lactovegetarian diets, which the authors proposed to be due to high intake of foods imported from high-Se areas [61]. Three other subsequent studies by a different group from Bratislava yielded opposite results in regard to plasma $\mathrm{Se}$ and other measures of Se status [65-68].

Another 'special case' study is an analysis in Finnish vegans and non-vegetarians [72]. It found lower serum Se in vegans; however, the mean values in both groups were noticeably higher than in other European studies. This is because Finland has national legislation which mandates adding Se to fertilizers [76].

The results of these and other identified published studies of Se status in European vegetarians, as well as their Se intakes assessed by duplicate diet analysis, are presented in Table 1. Currently, the most informative and commonly used biomarker of relevance to the antitumourigenic Se properties is plasma Se [29], and for the sake of clarity and comparability, the specific values obtained in these studies are presented in Table 1 for this parameter only. For reference, optimal plasma/serum Se is approximately $120 \mathrm{ng} / \mathrm{ml}$ and there is no evidence of cancer risk reduction due to increases above this level [29], while levels below $70 \mathrm{ng} / \mathrm{ml}$ are considered Se deficiency [58].

The results of two studies on Se status in European vegetarians merit particular attention. First, the 12 month trial assessing trace element status after adopting a lactovegetarian diet from Sweden provided strong evidence that adopting such a diet in the context of a low-Se area decreases Se status, as measured by plasma $\mathrm{Se}(76 \mathrm{ng} / \mathrm{ml}$ at baseline vs ca. $55 \mathrm{ng} / \mathrm{ml}$ after 1 year; read from figure) [71]. Second, a cross-sectional study from Germany found no significant differences in extracellular GPx3 activity between vegetarians and omnivores, but serum Se and SePP concentrations were significantly reduced in vegetarians (mean serum Se ca. 74 vs. $93 \mathrm{ng} / \mathrm{ml}$ in omnivores; read from figure) [69]-the latter being particularly relevant in the context of CRC [45].

The results of studies of Se status in European vegetarians show that Se status as assessed by plasma or serum is ca. 10-20\% lower in vegetarians than in non-vegetarians (but suboptimal in both diet groups), and highlight the considerable contribution of animal products to total Se intake in low-Se areas. However, this is not the case in areas with high soil Se. In contrast to the findings from Europe, North American studies [77, 78], including one study in Adventist vegetarians [78], suggested similar and optimal Se status in vegetarians and omnivores, as assessed by whole blood Se [77], as well as selenium content and GPx activity of milk from vegetarian and non-vegetarian women [78].

Overall, the results of European including some British studies convincingly suggest that lower Se status in British vegetarians than that of meat-eaters is very likely. 


\section{Changes in selenium intakes and status in the UK}

A dramatic decrease in the Se status in the UK had been observed over the 1980s in longitudinal studies on same subjects, from mean serum/plasma Se in the range of approximately $110-120 \mathrm{ng} / \mathrm{ml}$ in both healthy adults and renal dialysis patients at the beginning of this decade (which were then among the highest in European countries [79]) to as low as ca. $70 \mathrm{ng} / \mathrm{ml}$ in Scotland at the beginning of the 1990s [80-82]. A cross-sectional study from late 1980s of a random sample of 1000 adults registered within one general practice in Scotland has observed even lower mean plasma Se of only $60 \mathrm{ng} / \mathrm{ml}$ [83].

It should be noted that based on soil and foodstuffs $\mathrm{Se}$ content comparison, lower Se status can be expected in Scotland-where $10 \%$ of the EPIC-Oxford cohort reside [15]—than in other parts of the UK [84, 76]. However, the differences are likely not to be substantial. A comparison of Se status by UK region in the National Diet and Nutrition Survey (NDNS) 2000-2001 of a representative sample of the UK population found a difference of $5 \mathrm{ng} / \mathrm{ml}$ in mean plasma Se between the "London and the South East" region, for which the results were the highest, and Scotland [85].

Only one further study from Scotland assessing Se status was identified for comparability with these findings. It was published in the year 2000, but carried out in an unspecified period, and it found mean plasma Se concentrations of $82 \mathrm{ng} / \mathrm{ml}$ [86], which may have been due to differences between the study samples of this and the previous studies $[82,83]$ or due to an actual increase in Se content in the foodstuffs in the Scottish market. In the 2000-2001 NDNS, the mean plasma Se in Scotland was $86 \mathrm{ng} / \mathrm{ml}$ [85]. Given the representativeness of the NDNS samples, i.e. likely including some ill individuals whose Se status can be compromised due to illness, somewhat lower mean Se status can be expected in them than in healthy volunteers, who constituted the samples of most other studies on Se status in the UK discussed in the current review.

The following mean plasma Se concentrations were obtained in this and other editions of the NDNS for the whole UK: $75 \mathrm{ng} / \mathrm{ml}$ in non-institutionalized elderly between 1994 and 1995 [87], $87 \mathrm{ng} / \mathrm{ml}$ in adults between 2000 and 2001 [85] and $85 \mathrm{ng} / \mathrm{ml}$ in both adults and non-institutionalized elderly between 2008 and 2012 [20]. The negligible difference in plasma Se $(<1 \mathrm{ng} / \mathrm{ml})$ between the two groups suggests that the results of the 1994-1995 survey in the elderly [87] may have been due to a nadir of Se intake and status in the UK at that time, rather than lower Se status in the elderly than in younger adults. The findings of similar Se status in both groups in the 2008-2012 NDNS [20] are in agreement with other studies, which suggest that apparently healthy elderly subjects have similar $[88,89]$ or somewhat lower [90] Se status than younger adults.

The decrease in Se status in the UK was due to changes in Se content of food products available in the British market [91], largely resulting from the decline in imports of selenium rich wheat for breadmaking flour from North America [80].

The results of the UK Total Diet Study (TDS, a study of chemical analysis of commonly consumed foods, aiming to estimate mean nutrient contents of a typical diet) are not in full agreement with the findings on Se status in terms of the timing of Se intake/status decrease, suggesting that there was a steady Se content in British diets throughout the $1980 \mathrm{~s}$ at ca. $60 \mathrm{mcg} /$ day (although there seemed to be a decrease in Se status over this decade), with a sudden decrease (1991-1994) to ca. $40 \mathrm{mcg} /$ day in the 1990s up to early $2000 \mathrm{~s}$, and a subsequent increase to $58 \mathrm{mcg} / \mathrm{day}$ in the year 2006 [32, 92]. It should be noted that TDS do not provide robust trend data [83] and no changes in food supply between 1991 and 1994 were noted, which could explain the sudden decrease [32]. They were most likely the result of differences in the choice of foods purchased in TDS [32], possibly inflating the actual Se content estimate of the average British diet in the 1991 measurement.

Recent Se status studies from the UK in non-representative, healthy individuals suggest that there may have indeed been a rise in Se content of foods in the British market, reflected in plasma/serum Se concentrations in the 90-100 $\mathrm{ng} / \mathrm{ml}$ range [93]. Overall, there is strong evidence of a substantial decrease in Se intakes and status throughout 1980s and early 1990s in the UK, and some evidence of a reverse J-shaped curve of Se intakes/status over the last three decades; however, high-quality data to ascertain this are lacking. Moreover, no changes in food supply were identified, which could explain the proposed increases in Se intakes/status over the late 1990s and 2000s.

While the data presented so far are in agreement with the hypothesis proposed in this review, the experience of a nationwide addition of sodium selenite to fertilizers in Finland is the proverbial fly in the ointment. Universal use of fertilizers supplemented with inorganic Se was introduced in this country in 1985 due to very low Se soil content and Se intake [76]. No substantial changes were observed in cardiovascular mortality and cancer incidence trends, including the colon cancer incidence rate, however, as is always the case with such descriptive data, drawing causal inferences is severely limited. It can be argued that either other lifestyle and medical factors were stronger determinants of disease outcomes than the improvement of Se status, or that specifically sodium selenate had no appreciable effect on disease outcomes, which does not automatically rule out the possibility that other Se compounds might have favourably influenced these trends. 
Table 2 Temporal changes in Se intakes and Se status in adults, and CRC risk in vegetarians in the UK

\begin{tabular}{|c|c|c|c|}
\hline Years & $\begin{array}{l}\text { Se intake }{ }^{\mathrm{a}} \\
(\mu \mathrm{g} / \text { day })\end{array}$ & Changes in mean plasma/serum $\mathrm{Se}(\mathrm{ng} / \mathrm{ml})$ & Studies on CRC risk in British vegetarians \\
\hline \multicolumn{3}{|l|}{$1970 \mathrm{~s}$} & \multirow[t]{2}{*}{ HFSS follow-up begins } \\
\hline 1974 & \multicolumn{2}{|l|}{60} & \\
\hline $\begin{array}{r}1980 \mathrm{~s} \\
1985\end{array}$ & 63 & $\begin{array}{l}\text { Concentrations in the range of ca. 110-120 (among } \\
\text { the highest in Europe) begin to decrease }\end{array}$ & OVS follow-up begins \\
\hline $\begin{array}{r}1990 s \\
1991\end{array}$ & 60 & \multirow[t]{2}{*}{$\begin{array}{l}\text { Nadir of Se status with the lowest concentrations of } \\
60-70 \text { observed in Scotland (likely slightly lower } \\
\text { than in the rest of the UK) }\end{array}$} & \multirow[t]{3}{*}{ EPIC-Oxford study follow-up begins } \\
\hline 1994 & 43 & & \\
\hline 1995 & 39 & UK representative $^{\mathrm{b}}$ elderly $^{\mathrm{c}} 75$ & \\
\hline 1997 & 39 & Scotland: 82 & $\begin{array}{l}\text { CRC risk insignificantly lower in vegetarians by } 15 \% \text { in both } \\
\text { HFSS and OVS }\end{array}$ \\
\hline \multicolumn{4}{|l|}{$2000 \mathrm{~s}$} \\
\hline 2000 & 34 & \multicolumn{2}{|l|}{$\begin{array}{l}\text { UK representative }{ }^{\mathrm{b}} \text { adults: } 87 \text { (from } 86 \text { in Scotland to } \\
91 \text { in London and the South East) }\end{array}$} \\
\hline \multirow[t]{2}{*}{2006} & \multirow[t]{2}{*}{58} & & $\begin{array}{l}\text { EPIC-Oxford CRC RR in vegetarians after } 10.7 \text { years mean } \\
\text { follow-up: } 1.39 \text { (95\% CI: } 1.01-1.91)\end{array}$ \\
\hline & & & $\begin{array}{l}\text { EPIC-Oxford \& OVS combined CRC RR in vegetarians after } \\
12.2 \text { years mean follow-up: } 1.12 \text { (95\% CI: } 0.87-1.44)\end{array}$ \\
\hline \multirow[t]{2}{*}{$2010 \mathrm{~s}$} & & \multicolumn{2}{|l|}{$\begin{array}{l}\text { Concentrations in the ca. } 90-100 \text { range in healthy } \\
\text { individuals, indicating a possible increase in Se } \\
\text { status since the 1990s }\end{array}$} \\
\hline & & UK representative ${ }^{\mathrm{b}}$ adults and elderly ${ }^{\mathrm{c}}: 85$ both & $\begin{array}{l}\text { EPIC-Oxford \& OVS combined CRC RR in vegetarians after } \\
14.9 \text { years mean follow-up: } 1.03 \text { (95\% CI: } 0.84-1.28)\end{array}$ \\
\hline
\end{tabular}

\section{Are the patterns of Se intake associated with the secular trends of CRC risk in British vegetarians?}

As presented in Table 2, the patterns of CRC mortality or incidence in British vegetarians followed the presumed patterns of changes in Se intake/status in the UK. First, the HFSS and OVS, which were carried out mostly during the relatively high-Se period in the UK, observed not statistically significant, $15 \%$ lower CRC mortality rates in vegetarians than in non-vegetarians [7, 8]. Arguably, the sample sizes in both studies were insufficient to detect small to moderate differences in site-specific cancer rates.

Second, the EPIC-Oxford study in which increased CRC incidence was observed in vegetarians [9], started soon after the Se intake/status in the UK likely substantially decreased. When data from this point of follow-up in the EPIC-Oxford study were combined with data from the OVS, thus increasing the overall exposure of the study sample to Se, the relative incidence of CRC in vegetarians was $12 \%$ higher and no longer significant [10].

After additional follow-up, which took place during the period of possibly higher Se intake/status than the beginning of the EPIC-Oxford study [20, 32, 86, 87, 91, 92], the
CRC incidence in vegetarians relative to meat-eaters was virtually the same in the pooled data from the EPIC-Oxford study and OVS [11]. Moreover, the relative CRC incidence rate in vegans, who may be most at risk of low Se intakes in the UK [55], was 1.29 (0.81-2.07), albeit based only on 19 cases [11]. Also, this analysis showed 34\% lower CRC incidence in fish-eaters (pesco-vegetarians) than in meateaters, with the earlier pooled analysis [10] and EPICOxford study alone [9] showing insignificantly lower CRC incidence in this diet group.

Fish are a rich source of Se [61]; therefore, the lower $\mathrm{CRC}$ risk in British fish-eaters than in vegetarians is consistent with the proposed hypothesis of secular changes in Se status/intake modulating CRC risk. However, in the American Adventist Health Study 2, pesco-vegetarians also had significantly lower risk of CRC compared to nonvegetarians, while vegetarians did not [6]. Data on Se status of the cohort are not available and it is difficult to judge it based on the local soil Se concentrations, as the cohort is spread over the USA and Canada. Nevertheless, the Se status of Adventist cohorts is likely to be higher than in EPIC-Oxford, and hence the hypothesized positive impact of Se from fish is likely to be smaller in the USA, if at all 


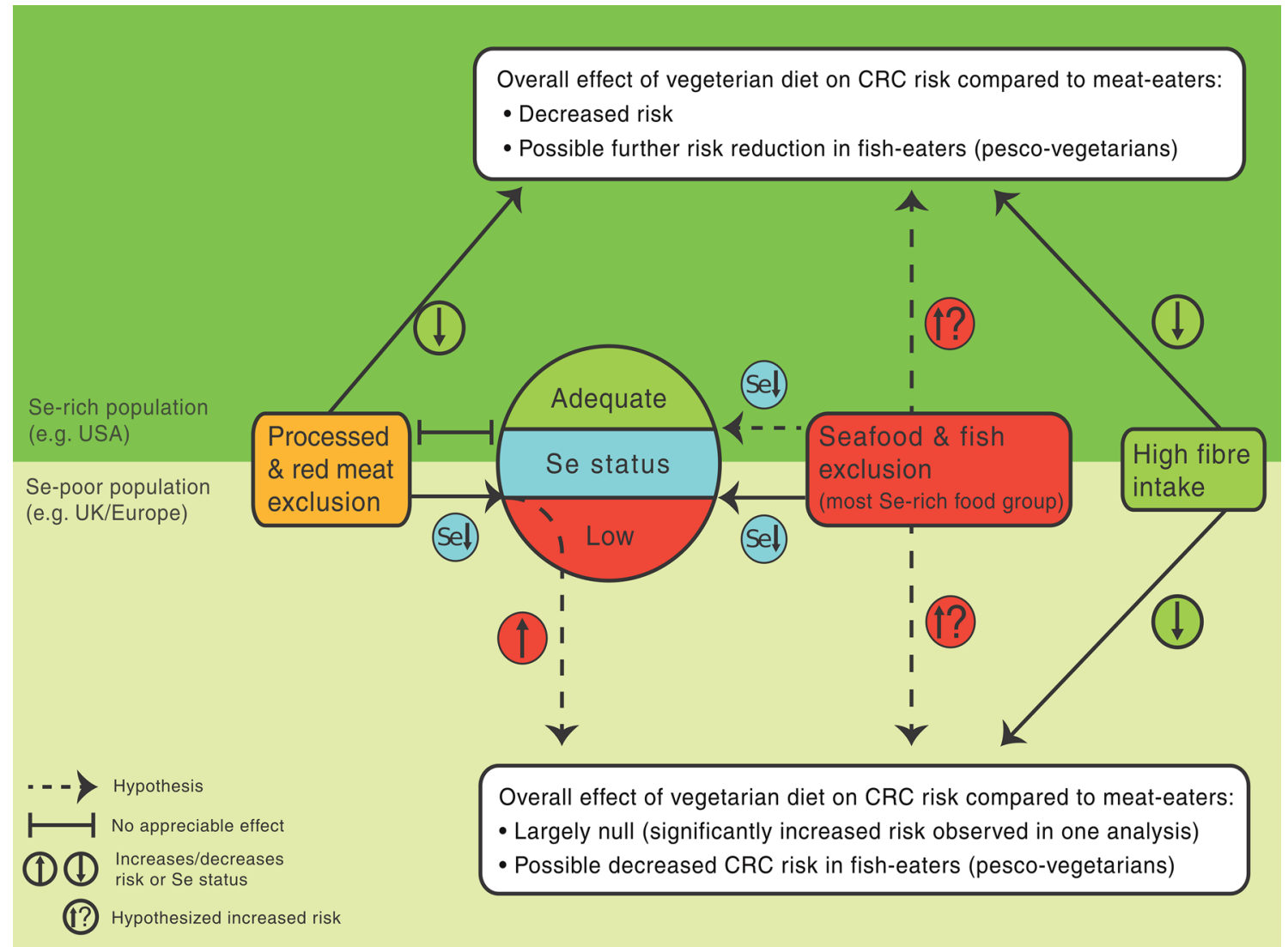

Fig. 1 Hypothesized effect modification of the influence of vegetarian diet and its components on colorectal cancer (CRC) risk by selenium (Se) status

existent. It is possible that other nutrients from fish (e.g. vitamin $\mathrm{D}$, omega-3 fatty acids), their synergistic effect (i.e. fish itself), or some other aspect of diet or lifestyle common to American and British fish-eaters/pesco-vegetarians reduces the CRC incidence in these diet groups.

There is some evidence available to support the notion that fish may decrease CRC risk when comparing extreme consumption levels [94], but not when estimating relative risks per $100 \mathrm{~g}$ or per times per week consumed [1]. It should be kept in mind that fish-eaters in the EPIC-Oxford study are "fish-allowers," rather than high fish consumers, with median fish intake of ca. $30 \mathrm{~g} /$ day in men and $24 \mathrm{~g} /$ day in women, which is similar to that of meat-eaters [95]. 24-30 g of fish translates to up to $21-26 \mu \mathrm{g}$ of Se in the case of tuna [32], which is substantial compared to both recommended and usual Se intakes in the UK, while not representing a particularly high fish intake.

\section{Conclusions}

Whether or not Se status influences CRC risk in humans is a matter of ongoing debate. Null results in studies of CRC risk in British vegetarians $[7,8,10,11]$ are in disagreement with the established effects of fibre, and processed and red meats on the risk of this type of cancer [1]. Se status represents possibly the most pronounced difference in nutritional status between British (likely low Se status) and American vegetarians (likely adequate Se status), in whom significantly decreased CRC risk has been observed [5, 6]. Figure 1 shows the hypothesized effect modification of the influence of vegetarian diet on CRC risk by high- or low-Se area.

Authors of one of the European studies on Se status in vegetarians went as far as to suggest that "Se supplementation should be recommended to this risk group [vegetarians] of the population" [65]. While undoubtedly Se is a micronutrient of concern in plant-based diets in Se-poor areas, it should be kept in mind that ensuring adequate vitamin $B_{12}$ supplementation (or planning of the diet in regard to fortified foods) is of primary importance both in vegans and considerable proportion of vegetarians. This basic need is often unmet, as reflected by depletion or deficiency rates in vegetarian populations ranging $10-90 \%$ - depending on the criterion of deficiency used and life-stage group under study, but regardless of type of vegetarian diet [96]. Thus, 
a food-based recommendation is desirable and Brazil nuts have been shown to improve Se status [97]. Depending on the soil Se concentration in the country of origin, Brazil nuts may have moderate to high-Se content, ranging from $8 \mathrm{mcg} / \mathrm{nut}(5 \mathrm{~g})$ in nuts grown in Bolivia, through $18 \mathrm{mcg} /$ nut in Brazil and 33mcg/nut in Peru, to $130 \mathrm{mcg} / \mathrm{nut}$ when grown in northern countries of South America [98]. Either adequate, country of origin-dependant, "dosing" of Brazil nuts or use of dietary supplements should be exercised by plant-based diet followers in low-Se areas.

Changes in relative risk of CRC in British vegetarians follow the patterns of changes in Se intakes and status in the $\mathrm{UK}$; therefore, the hypothesis that Se status in British vegetarians may influence their CRC risk is worthy of pursuing in future studies. The ongoing EPIC-Oxford study allows for such an opportunity, as blood samples were provided by 19,500 of its participants. A biomarker based study of CRC risk in this population would cover a wide range of intakes, thus making a substantial contribution to the body of evidence on the relationship between Se and CRC.

Acknowledgements The author was supported by private sponsorship covering living expenses from $\mathrm{Mr}$ and Mrs Andrzej and Beata Gajek. The author would like to thank Małgorzata Desmond, Dr Kathryn Bradbury and Damian Parol for their valuable comments and suggestions on the draft of the manuscript. The author would also like to thank the anonymous reviewers, whose scrutiny and constructive criticism greatly improved the manuscript. Andrzej Kucharzyk is acknowledged for his engagement in creating the figure for this manuscript.

\section{Compliance with ethical standards}

Conflict of interest The author declares no conflict of interest.

Open Access This article is distributed under the terms of the Creative Commons Attribution 4.0 International License (http://creativecommons.org/licenses/by/4.0/), which permits unrestricted use, distribution, and reproduction in any medium, provided you give appropriate credit to the original author(s) and the source, provide a link to the Creative Commons license, and indicate if changes were made.

\section{References}

1. World Cancer Research Fund/American Institute for Cancer Research (2011) Continuous Update Project Report. Food, Nutrition, Physical Activity, and the Prevention of Colorectal Cancer. http://www.wcrf.org/sites/default/files/Colorectal-Cancer-2011-Report.pdf. Accessed 23 Nov 2015

2. International Agency for Research on Cancer (2015) Volume 114: Consumption of red meat and processed meat. IARC Working Group, Lyon, pp 6-13

3. Parkin DM, Boyd L, Walker LC (2011) 16. The fraction of cancer attributable to lifestyle and environmental factors in the UK in 2010. Br J Cancer 105(Suppl 2):S77-S81. doi:10.1038/ bjc. 2011.489
4. Key TJ, Fraser GE, Thorogood M, Appleby PN, Beral V, Reeves G, Burr ML, Chang-Claude J, Frentzel-Beyme R, Kuzma JW, Mann J, McPherson K (1998) Mortality in vegetarians and non-vegetarians: a collaborative analysis of 8300 deaths among 76,000 men and women in five prospective studies. Public Health Nutr 1:33-41

5. Singh PN, Fraser GE (1998) Dietary risk factors for colon cancer in a low-risk population. Am J Epidemiol 148:761-774

6. Orlich MJ, Singh PN, Sabaté J, Fan J, Sveen L, Bennett H, Knutsen SF, Beeson WL, Jaceldo-Siegl K, Butler TL, Herring RP, Fraser GE (2015) Vegetarian dietary patterns and the risk of colorectal cancers. JAMA Intern Med 175:767-776. doi:10.1001/jamainternmed.2015.59

7. Appleby PN, Key TJ, Thorogood M, Burr ML, Mann J (2002) Mortality in British vegetarians. Public Health Nutr 5:29-36

8. Sanjoaquin MA, Appleby PN, Thorogood M, Mann JI, Key TJ (2004) Nutrition, lifestyle and colorectal cancer incidence: a prospective investigation of 10998 vegetarians and nonvegetarians in the United Kingdom. Br J Cancer 90:118-121

9. Key TJ, Appleby PN, Spencer EA, Travis RC, Roddam AW, Allen NE (2009) Cancer incidence in vegetarians: results from the European Prospective Investigation into Cancer and Nutrition (EPIC-Oxford). Am J Clin Nutr 89(suppl):1S-7S

10. Key TJ, Appleby PN, Spencer EA, Travis RC, Allen NE, Thorogood M, Mann JI (2009) Cancer incidence in British vegetarians. Br J Cancer 101:192-197. doi:10.1038/sj.bjc.6605098

11. Key TJ, Appleby PN, Crowe FL, Bradbury KE, Schmidt JA, Travis RC (2014) Cancer in British vegetarians: updated analyses of 4998 incident cancers in a cohort of 32,491 meat eaters, 8612 fish eaters, 18,298 vegetarians, and 2246 vegans. Am J Clin Nutr 100(Suppl 1):378S-385S. doi:10.3945/ajen.113.071266

12. Key TJ, Appleby PN, Spencer EA, Travis RC, Roddam AW, Allen NE (2009) Mortality in British vegetarians: results from the European Prospective Investigation into Cancer and Nutrition (EPIC-Oxford). Am J Clin Nutr 89:1613S-1619S. doi:10.3945/ ajen.2009.26736L

13. Thorogood M, Mann J, Appleby P, McPherson K (1994) Risk of death from cancer and ischaemic heart disease in meat and nonmeat eaters. Br Med J 308:1667-1670

14. Key TJ, Thorogood M, Appleby PN, Burr ML (1996) Dietary habits and mortality in 11000 vegetarians and health conscious people: results of a 17 year follow up. Br Med J 313:775-779

15. Davey GK, Spencer EA, Appleby PN, Allen NE, Knox KH, Key TJ (2003) EPIC-Oxford: lifestyle characteristics and nutrient intakes in a cohort of 33883 meat-eaters and 31546 non meateaters in the UK. Public Health Nutr 6:259-269

16. Yee YK, Tan VP, Chan P, Hung IF, Pang R, Wong BC (2009) Epidemiology of colorectal cancer in Asia. J Gastroenterol Hepatol 24:1810-1816

17. Bryan NS (2011) Letter by Bryan regarding article, "red and processed meat consumption and risk of incident coronary heart disease, stroke, and diabetes mellitus: a systematic review and meta-analysis". Circulation 123:e16

18. Fraser GE (2009) Vegetarian diets: what do we know of their effects on common chronic diseases? Am J Clin Nutr 89:1607S-1612S. doi:10.3945/ajcn.2009.26736K

19. Slimani N, Fahey M, Welch AA, Wirfält E, Stripp C, Bergström E, Linseisen J, Schulze MB, Bamia C, Chloptsios Y, Veglia F, Panico S, Bueno-de-Mesquita HB, Ocké MC, Brustad M, Lund E, González CA, Barcos A, Berglund G, Winkvist A, Mulligan A, Appleby P, Overvad K, Tjønneland A, Clavel-Chapelon F, Kesse E, Ferrari P, Van Staveren WA, Riboli E (2002) Diversity of dietary patterns observed in the European Prospective Investigation into Cancer and Nutrition (EPIC) project. Public Health Nutr 5:1311-1328 
20. Bates B, Lennox A, Prentice A, Bates C, Page P, Nicholson S, Swan G (2014) National diet and nutrition survey results from years 1, 2, 3 and 4 (combined) of the rolling programme (2008/2009-2011/2012). Public Health England, Food Standards Agency, London

21. Sobiecki JG, Appleby PN, Bradbury KE, Key TJ (2016) High compliance with dietary recommendations in a cohort of meat eaters, fish eaters, vegetarians, and vegans: results from the European Prospective Investigation into Cancer and Nutrition-Oxford study. Nutr Res 36:464-477. doi:10.1016/j.nutres.2015.12.016

22. Rizzo NS, Jaceldo-Siegl K, Sabate J, Fraser GE (2013) Nutrient profiles of vegetarian and nonvegetarian dietary patterns. J Acad Nutr Diet 113:1610-1619. doi:10.1016/j.jand.2013.06.349

23. Rayman MP (2008) Food-chain selenium and human health: emphasis on intake. Br J Nutr 100:254-268

24. Rayman MP (2012) Selenium and human health. Lancet 379:1256-1268. doi:10.1016/S0140-6736(11)61452-9

25. Department of Health (1991) Dietary reference values for food energy and nutrients for the United Kingdom. Report of the panel on dietary reference values. Report on health and social subjects No 41. HMSO, London

26. Rayman MP (2005) Selenium in cancer prevention: a review of the evidence and mechanism of action. Proc Nutr Soc 64:527-542

27. Joosen AM, Kuhnle GG, Aspinall SM, Barrow TM, Lecommandeur E, Azqueta A, Collins AR, Bingham SA (2009) Effect of processed and red meat on endogenous nitrosation and DNA damage. Carcinogenesis 30:1402-1407. doi:10.1093/carcin/ bgp 130

28. Gratz SW, Wallace RJ, El-Nezami HS (2011) Recent perspectives on the relations between fecal mutagenicity, genotoxicity, and diet. Front Pharmacol 2:4. doi:10.3389/fphar.2011.00004

29. Sanjoaquin MA, Appleby PN, Spencer EA, Key TJ (2004) Nutrition and lifestyle in relation to bowel movement frequency: a cross-sectional study of 20630 men and women in EPIC-Oxford. Public Health Nutr 7:77-83

30. Combs GF Jr (2015) Biomarkers of selenium status. Nutrients 7:2209-2236. doi:10.3390/nu7042209

31. World Cancer Research Fund/American Institute for Cancer Research (2007) Food, nutrition, physical activity, and the prevention of cancer: a global perspective. AICR, Washington, DC

32. World Cancer Research Fund International/American Institute for Cancer Research (2014) Continuous Update Project Report: Diet, Nutrition, Physical Activity, and Prostate Cancer. www. wcrf.org/sites/default/files/Prostate-Cancer-2014-Report.pdf. Accessed 23 Nov 2015

33. Scientific Advisory Committee on Nutrition Position Statement on Selenium and Health. https://www.gov.uk/government/publications/sacn-statement-on-selenium-and-health-2013. Accessed 23 Nov 2015

34. Vinceti M, Dennert G, Crespi CM, Zwahlen M, Brinkman M, Zeegers MP, Horneber M, D'Amico R, Del Giovane C (2014) Selenium for preventing cancer. Cochrane Database Syst Rev 3:CD005195. doi:10.1002/14651858.CD005195.pub3

35. Clark LC, Combs GF Jr, Turnbull BW, Slate EH, Chalker DK, Chow J, Davis LS, Glover RA, Graham GF, Gross EG, Krongrad A, Lesher JL Jr, Park HK, Sanders BB Jr, Smith CL, Taylor JR (1996) Effects of selenium supplementation for cancer prevention in patients with carcinoma of the skin. A randomized controlled trial. JAMA 276:1957-1963

36. Duffield-Lillico AJ, Reid ME, Turnbull BW, Combs GF Jr, Slate EH, Fischbach LA, Marshall JR, Clark LC (2002) Baseline characteristics and the effect of selenium supplementation on cancer incidence in a randomized clinical trial: a summary report of the Nutritional Prevention of Cancer Trial. Cancer Epidemiol Biomarkers Prev 11:630-639
37. Reid ME, Duffield-Lillico AJ, Garland L, Turnbull BW, Clark LC, Marshall JR (2002) Selenium supplementation and lung cancer incidence: an update of the nutritional prevention of cancer trial. Cancer Epidemiol Biomark Prev 11:1285-1291

38. Lippman SM, Klein EA, Goodman PJ, Lucia MS, Thompson IM, Ford LG, Parnes HL, Minasian LM, Gaziano JM, Hartline JA, Parsons JK, Bearden JD III, Crawford ED, Goodman GE, Claudio J, Winquist E, Cook ED, Karp DD, Walther P, Lieber MM, Kristal AR, Darke AK, Arnold KB, Ganz PA, Santella RM, Albanes D, Taylor PR, Probstfield JL, Jagpal TJ, Crowley JJ, Meyskens FL Jr, Baker LH, Coltman CA Jr (2009) Effect of selenium and vitamin E on risk of prostate cancer and other cancers: the Selenium and Vitamin E Cancer Prevention Trial (SELECT). JAMA 301:39-51. doi:10.1001/ jama.2008.864

39. Duffield-Lillico AJ, Dalkin BL, Reid ME, Turnbull BW, Slate EH, Jacobs ET, Marshall JR, Clark LC, Nutritional Prevention of Cancer Study Group (2003) Selenium supplementation, baseline plasma selenium status and incidence of prostate cancer: an analysis of the complete treatment period of the Nutritional Prevention of Cancer Trial. BJU Int 91:608-612

40. Méplan C (2015) Selenium and chronic diseases: a nutritional genomics perspective. Nutrients 7:3621-3651. doi:10.3390/ nu7053621

41. Allen NE, Ruth CT, Appleby, Albanes D, Barnett MJ, Black A, Bueno-de-Mesquita HB, Deschasaux M, Galan P, Goodman GE, Goodman PJ, Gunter MJ, Heliövaara M, Helzlsouer KJ, Henderson BE, Hercberg S, Knekt P, Kolonel LN, Lasheras C, Linseisen J, Metter EJ, Neuhouser ML, Olsen A, Pala V, Platz EA, Rissanen H, Reid ME, Schenk JM, Stampfer MJ, Stattin $\mathrm{P}$, Tangen CM, Touvier M, Trichopoulou A, van den Brandt PA, Key TJ; Endogenous Hormones, Nutritional Biomarkers and Prostate Cancer Collaborative Group (2016) Selenium and prostate cancer: analysis of individual participant data from fifteen prospective studies. J Natl Cancer Inst 108(11). doi: 10.1093/jnci/djw153. Print Nov 2016

42. Bleys J, Navas-Acien A, Guallar E (2008) Serum selenium levels and all-cause, cancer, and cardiovascular mortality among US adults. Arch Intern Med 168:404-410

43. Hatfield DL, Tsuji PA, Carlson BA, Gladyshev VN (2014) Selenium and selenocysteine: roles in cancer, health, and development. Trends Biochem Sci 39:112-120. doi:10.1016/j. tibs.2013.12.007

44. Bekaert B, Rayman MP (2009) Plasma selenium concentration and prostate cancer risk. Am J Clin Nutr 89:1276-1277. doi:10.3945/ajen.2009.27443

45. Hughes DJ, Fedirko V, Jenab M, Schomburg L, Méplan C, Freisling H, Bueno-de-Mesquita HB, Hybsier S, Becker NP, Czuban M, Tjønneland A, Outzen M, Boutron-Ruault MC, Racine A, Bastide N, Kühn T, Kaaks R, Trichopoulos D, Trichopoulou A, Lagiou P, Panico S, Peeters PH, Weiderpass E, Skeie G, Dagrun E, Chirlaque MD, Sánchez MJ, Ardanaz E, Ljuslinder I, Wennberg M, Bradbury KE, Vineis P, Naccarati A, Palli D, Boeing H, Overvad K, Dorronsoro M, Jakszyn P, Cross AJ, Quirós JR, Stepien M, Kong SY, Duarte-Salles T, Riboli E, Hesketh JE (2015) Selenium status is associated with colorectal cancer risk in the European prospective investigation of cancer and nutrition cohort. Int J Cancer 136:1149-1161. doi:10.1002/ ijc. 29071

46. Fairweather-Tait SJ, Bao Y, Broadley MR, Collings R, Ford D, Hesketh JE, Hurst R (2011) Selenium in human health and disease. Antioxid Redox Signal 14:1337-1383. doi:10.1089/ ars. 2010.3275

47. Rayman MP, Infante HG, Sargent M (2008) Food-chain selenium and human health: spotlight on speciation. Br J Nutr 100:238-253. doi:10.1017/S0007114508922522 
48. Fairweather-Tait SJ, Collings R, Hurst R (2010) Selenium bioavailability: current knowledge and future research requirements. Am J Clin Nutr 91:1484S-1491S. doi:10.3945/ajen.2010.28674J

49. Wrobel JK, Power R, Toborek M (2016) Biological activity of selenium: revisited. IUBMB Life 68:97-105. doi:10.1002/ iub. 1466

50. Weekley CM, Harris HH (2013) Which form is that? The importance of selenium speciation and metabolism in the prevention and treatment of disease. Chem Soc Rev 42:8870-8894. doi: $10.1039 / \mathrm{c} 3 \operatorname{cs} 60272 \mathrm{a}$

51. Sneddon A (2012) Selenium nutrition and its impact on health. Food and Health Innovation Service (FHIS), Aberdeen, UK, p 6

52. Bryszewska MA, Måge A (2015) Determination of selenium and its compounds in marine organisms. J Trace Elem Med Biol 29:91-98

53. Marshall JR, Ip C, Romano K, Fetterly G, Fakih M, Jovanovic B, Perloff M, Crowell J, Davis W, French-Christy R, Dew A, Coomes M, Bergan R (2011) Methyl selenocysteine: single-dose pharmacokinetics in men. Cancer Prev Res (Phila) 4:1938-1944. doi:10.1158/1940-6207

54. Richie JP Jr, Das A, Calcagnotto AM, Sinha R, Neidig W, Liao J, Lengerich EJ, Berg A, Hartman TJ, Ciccarella A, Baker A, Kaag MG, Goodin S, DiPaola RS, El-Bayoumy K (2014) Comparative effects of two different forms of selenium on oxidative stress biomarkers in healthy men: a randomized clinical trial. Cancer Prev Res (Phila) 7:796-804. doi:10.1158/1940-6207

55. Ministry of Agriculture, Fisheries and Food, UK (2000) Duplicate diet study of vegetarians-dietary exposures to 12 metals and other elements. Food Surveillance Info Sheet No 193

56. Ministry of Agriculture, Fisheries and Food, UK (1999) 1997 Total Diet Study-Aluminium, arsenic, cadmium, chromium, copper, lead, mercury, nickel, selenium, tin and zinc. Food Surveillance Information Sheet No 191

57. Lightowler HJ, Davies GJ (2000) Micronutrient intakes in a group of UK vegans and the contribution of self-selected dietary supplements. J R Soc Promot Health 120:117-124

58. Food and Nutrition Board, Institute of Medicine (2000) Dietary reference intakes for vitamin $\mathrm{C}$, vitamin $\mathrm{E}$, selenium, and carotenoids. National Academy Press, Washington, DC

59. Roekens EJ, Robberecht HJ, Deelstra HA (1986) Dietary selenium intake in Belgium for different population groups at risk for deficiency. Z Lebensm Unters Forsch 182:8-13

60. Abdulla M, Andersson I, Asp NG, Berthelsen K, Birkhed D, Dencker I, Johansson CG, Jägerstad M, Kolar K, Nair BM, Nilsson-Ehle P, Nordén A, Rassner S, Akesson B, Ockerman PA (1981) Nutrient intake and health status of vegans. Chemical analyses of diets using the duplicate portion sampling technique. Am J Clin Nutr 34:2464-2477

61. Holland B, Brown JB, Buss DH (1993) Fish and fish products. Third supplement to McCance and Widdowson's the composition of foods, 5th edn. Royal Society of Chemistry, Cambridge

62. Abdulla M, Aly KO, Andersson I, Asp NG, Birkhed D, Denker I, Johansson CG, Jägerstad M, Kolar K, Nair BM et al (1984) Nutrient intake and health status of lactovegetarians: chemical analyses of diets using the duplicate portion sampling technique. Am J Clin Nutr 40:325-338

63. Judd PA, Long A, Butcher M, Caygill CP, Diplock AT (1997) Vegetarians and vegans may be most at risk from low selenium intakes. BMJ 314:1834

64. Allen NE, Appleby PN, Roddam AW, Tjønneland A, Johnsen NF, Overvad K, Boeing H, Weikert S, Kaaks R, Linseisen J, Trichopoulou A, Misirli G, Trichopoulos D, Sacerdote C, Grioni S, Palli D, Tumino R, Bueno-de-Mesquita HB, Kiemeney LA, Barricarte A, Larrañaga N, Sánchez MJ, Agudo A, Tormo MJ, Rodriguez L, Stattin P, Hallmans G, Bingham S, Khaw KT, Slimani N, Rinaldi S, Boffetta P, Riboli E, Key TJ (2008) Plasma selenium concentration and prostate cancer risk: results from the European Prospective Investigation into Cancer and Nutrition (EPIC). Am J Clin Nutr 88:1567-1575. doi:10.3945/ajcn.2008.26205

65. Kadrabová J, Madaric A, Kováciková Z, Ginter E (1995) Selenium status, plasma zinc, copper, and magnesium in vegetarians. Biol Trace Elem Res 50:13-24

66. Kováciková Z, Cerhata D, Kadrabová J, Madaric A, Ginter E (1998) Antioxidant status in vegetarians and nonvegetarians in Bratislava region (Slovakia). Z Ernahrungswiss 37:178-182

67. Nagyova A, Ginter E, Kovacikova Z (1995) Low glutathione levels and decreased glutathione peroxidase activity in the blood of vegetarians. Int J Vitam Nutr Res 65:221

68. Mangels R, Messina V, Messina M (2011) Chapter 6. Minerals. Selenium. In: Mangels R, Messina V, Messina M (ed) The dietitian's guide to vegetarian diets. 3rd edn. Jones \& Bartlett Learning, Sudbury, MA, pp 153-155

69. Hoeflich J, Hollenbach B, Behrends T, Hoeg A, Stosnach H, Schomburg L (2010) The choice of biomarkers determines the selenium status in young German vegans and vegetarians. Br J Nutr 104:1601-1604. doi:10.1017/S0007114510002618

70. Akesson B, Ockerman PA (1985) Selenium status in vegans and lactovegetarians. Br J Nutr 53:199-205

71. Srikumar TS, Johansson GK, Ockerman PA, Gustafsson JA, Akesson B (1992) Trace element status in healthy subjects switching from a mixed to a lactovegetarian diet for $12 \mathrm{mo}$. Am J Clin Nutr 55:885-890

72. Elorinne AL, Alfthan G, Erlund I, Kivimäki H, Paju A, Salminen I, Turpeinen U, Voutilainen S, Laakso J (2016) Food and nutrient intake and nutritional status of finnish vegans and nonvegetarians. PLoS ONE 11(2):e0148235. doi:10.1371/journal. pone. 0148235

73. Krajcovicová-Kudlácková M, Simoncic R, Babinská K, Béderová A, Brtková A, Magálová T, Grancićová E (1995) Selected vitamins and trace elements in blood of vegetarians. Ann Nutr Metab 39:334-339

74. Krajcovicová-Kudlácková M, Béderová A, Simoncic R, Babinská K, Magálová T, Brtková A (1995) Selected biochemical parameters in the blood of adolescent vegetarians. Czech Pediatr 10:323-327

75. Cade JE, Burley VJ, Greenwood DC, UK Women's Cohort Study Steering Group (2004) The UK Women's Cohort Study: comparison of vegetarians, fish-eaters and meat-eaters. Public Health Nutr 7:871-878

76. Alfthan G, Eurola M, Ekholm P, Venäläinen ER, Root T, Korkalainen K, Hartikainen H, Salminen P, Hietaniemi V, Aspila P, Aro A, Selenium Working Group (2015) Effects of nationwide addition of selenium to fertilizers on foods, and animal and human health in Finland: from deficiency to optimal selenium status of the population. J Trace Elem Med Biol 31:142-147. doi:10.1016/j.jtemb.2014.04.009

77. Shultz TD, Leklem JE (1983) Selenium status of vegeterians, nonvegetarians, and hormone-dependent cancer subjects. Am J Clin Nutr 37:114-118

78. Debski B, Finley DA, Picciano MF, Lönnerdal B, Milner J (1989) Selenium content and glutathione peroxidase activity of milk from vegetarian and nonvegetarian women. J Nutr 119:215-220

79. Thorling EB, Overvad K, Geboers J (1986) Selenium status in Europe-human data. A multicenter study. Ann Clin Res 18:3-7

80. Rayman MP (1997) Dietary selenium: time to act. BMJ 314:387-388

81. Momcilovic B, Miller PF, Day JP, Ackrill P (1991) Selenium status of renal dialysis patients. In: Momcilovic B (ed) Trace elements in man and animals (TEMA 7). IMI Institute For Medical Research and Occupational Health, University of Zagreb, Zagreb, pp 22-24 
82. MacPherson A, Barclay MNI (1997) Loss of Canadian wheat imports lowers selenium intake and status of the Scottish population. In: Fischer PWF, L'AlAbbé MR, Cockell KA, Gibson RS (eds) Trace elements in man and animals-9 (TEMA 9). NRC Research Press, Ottawa

83. Shortt CT, Duthie GG, Robertson JD, Morrice PC, Nicol F, Arthur JR (1997) Selenium status of a group of Scottish adults. Eur J Clin Nutr 51:400-404

84. Fordyce FM, Brereton N, Hughes J, Reay G, Thomas L, Walker A, Luo W, Lewis J (2009) The selenium content of scottish soil and food products. Food Standards Agency Scotland, Aberdeen

85. Rushton D, Henderson L, Gregory J, Bates CJ, Prentice A, Birch M, Swan G, Farron M (2004) The National Diet and Nutritional Survey: adults aged 19-64 years. Volume 4: Nutritional Status (anthropometry and blood analytes), blood pressure and physical activity. TSO, London

86. Brown KM, Pickard K, Nicol F, Beckett GJ, Duthie GG, Arthur JR (2000) Effects of organic and inorganic selenium supplementation on selenoenzyme activity in blood lymphocytes, granulocytes, platelets and erythrocytes. Clin Sci (Lond) 98(5):593-599

87. Bates CJ, Thane CW, Prentice A, Delves HT (2002) Selenium status and its correlates in a British national diet and nutrition survey: people aged 65 years and over. J Trace Elem Med Biol $16: 1-8$

88. Cals MJ, Succari M, Meneguzzer E, Ponteziere C, Bories PN, Devanlay M, Desveaux N, Gatey M, Luciani L, Blonde-Cynober F, Coudray-Lucas C (1997) Markers of oxidative stress in fit, health-conscious elderly people living in the Paris area. The Research Group on Ageing (GERBAP). Nutrition 13:319-326

89. Ducros V, Faure P, Ferry M, Couzy F, Biajoux I, Favier A (1997) The sizes of the exchangeable pools of selenium in elderly women and their relation to institutionalization. $\mathrm{Br} \mathrm{J}$ Nutr 78:379-396
90. Campbell D, Bunker VW, Thomas AJ, Clayton BE (1989) Selenium and vitamin $\mathrm{E}$ status of healthy and institutionalized elderly subjects: analysis of plasma, erythrocytes and platelets. Br J Nutr 62:221-227

91. Barclay MNI, MacPherson A, Dixon J (1995) Selenium content of a range of UK foods. J Food Comp Anal 8:307-318

92. Food Standards Agency (2009) Survey on measurement of the concentrations of metals and other elements from the 2006 UK total diet study. Food Survey Information Sheet 01/09. Food Standards Agency, London

93. Stoffaneller R, Morse NL (2015) A review of dietary selenium intake and selenium status in Europe and the Middle East. Nutrients 7:1494-1537. doi:10.3390/nu7031494

94. Wu S, Feng B, Li K, Zhu X, Liang S, Liu X, Han S, Wang B, Wu K, Miao D, Liang J, Fan D (2012) Fish consumption and colorectal cancer risk in humans: a systematic review and meta-analysis. Am J Med 125(551-9):e5. doi:10.1016/j.amjmed.2012.01.022

95. Schmidt JA, Crowe FL, Appleby PN, Key TJ, Travis RC (2013) Serum uric acid concentrations in meat eaters, fish eaters, vegetarians and vegans: a cross-sectional analysis in the EPIC-Oxford cohort. PLoS ONE 8:e56339. doi:10.1371/journal.pone.0056339

96. Pawlak R, Parrott SJ, Raj S, Cullum-Dugan D, Lucus D (2013) How prevalent is vitamin $\mathrm{B}(12)$ deficiency among vegetarians? Nutr Rev 71:110-117. doi:10.1111/nure.12001

97. Thomson CD, Chisholm A, McLachlan SK, Campbell JM (2008) Brazil nuts: an effective way to improve selenium status. Am J Clin Nutr 87:379-384

98. Parekh PP, Khan AR, Torre MA, Kitto ME (2008) Concentration of selenium, barium, and radium in Brazil nuts. J Food Comp Anal 21:332-335 